London scene in particular. This serious and informative account promises to be the standard biography for many years to come. Owen Gingerich is at the Harvard-Smithsonian Center for Astrophysics, Cambridge, Massachusetts 02138, USA.

\section{Brains trust}

\section{The Central Nervous System of Vertebrates}

by R. Nieuwenhuys, H. J. ten Donkelaar and C. Nicholson

Springer: 1997. Three volumes. Pp. 2,219. £942, \$1,595

\section{Glenn Northcutt}

At a time when many scientists debate what constitutes an LPU - least publishable unit — this work, consisting of more than 2,000 pages in threevolumes, must at least meet the minimal requirements. Such monumental surveys of the variation in the central nervous systems of vertebrates have been attempted several times.

In 1920, Cornelius Ubbo Ariëns Kappers, the first director of the famous Dutch Central Institute for Brain Research in Amsterdam, produced a two-volume work entitled Vergleichende Anatomie des Nervensystems which would form the core of a later expansion in 1936 by G. Carl Huber and Elizabeth C. Crosby. This three-volume work, The Comparative Anatomy of the Nervous System of Vertebrates, became a tombstone for the field - surely one could not write three volumes on the nervous systems of vertebrates without everything being said. Nothing could have been further from the truth. These surveys were based on descriptive histology which is particularly refractory to the analysis of microstructure and the interconnections of various parts of the nervous system.

Although the Kappers, Huber and Crosby volumes continued to be used during the 1960s, much of the original work and illustrations were badly out of date, and the material was not set within a broader biological context. These inadequacies were exacerbated by a renaissance of new techniques that allowed pathways to be experimentally established, neurotransmitters and their enzymes to be visualized, the ultrastructure of neurons and their processes to be examined in far greater detail than previously possible, and the refinement of electrophysiological techniques. Renewed interest in the development of nervous systems and their genetic underpinnings has further intensified the need for a new survey.

The new synthesis by R. Nieuwenhuys and colleagues is stunning and represents a level of scholarship that is rarely achieved in any field. The authors clearly outline the purpose and plan of this work by dividing it into three main sections: general features of the cellular elements that form the nervous systems of vertebrates and the general principles that guide their interpretation; detailed descriptions of the brains of selected species of all groups of vertebrates; and possible directions for future research. The quality and uniformity of the illustrations are remarkable.

Seven chapters form the general introductory part of this work. The topics range from the structure and function of the cell types that compose nervous systems and their morphogenesis to the general biological framework within which comparative neurobiologists analyse these systems. These chapters will be invaluable to the novice, who may know little about the organization and functions of neural cells, as well as to more advanced students who understand the basic structure of neural cells but have little idea of how they are generated.

The final chapter in this section outlines the goals of comparative neurobiologists and discusses how a new method of comparison,

cladistics, initially generated in another biological field, is being used by neurobiologists to gain a deeper understanding of neural evolution. This chapter will be of immense value to contemporary neurobiologists and, ironically, will also constitute a comprehensive statement for historians of the biological sciences who could otherwise only guess the goals and programmes of comparative neurobiology at the end of the twentieth century.

The second section has 15 chapters summarizing the central nervous systems of amphioxus and representatives of all groups of vertebrates. These chapters follow a general pattern in which the life history of one or more species of a group is briefly summarized, and standard views of their brains are presented, followed by a sequence of drawings of transversely sectioned tissue from the spinal cords and brains of these same species. The authors have adopted a standard way of illustrating the various brain levels by primarily using line drawings rather than photomicrographs. Some readers will

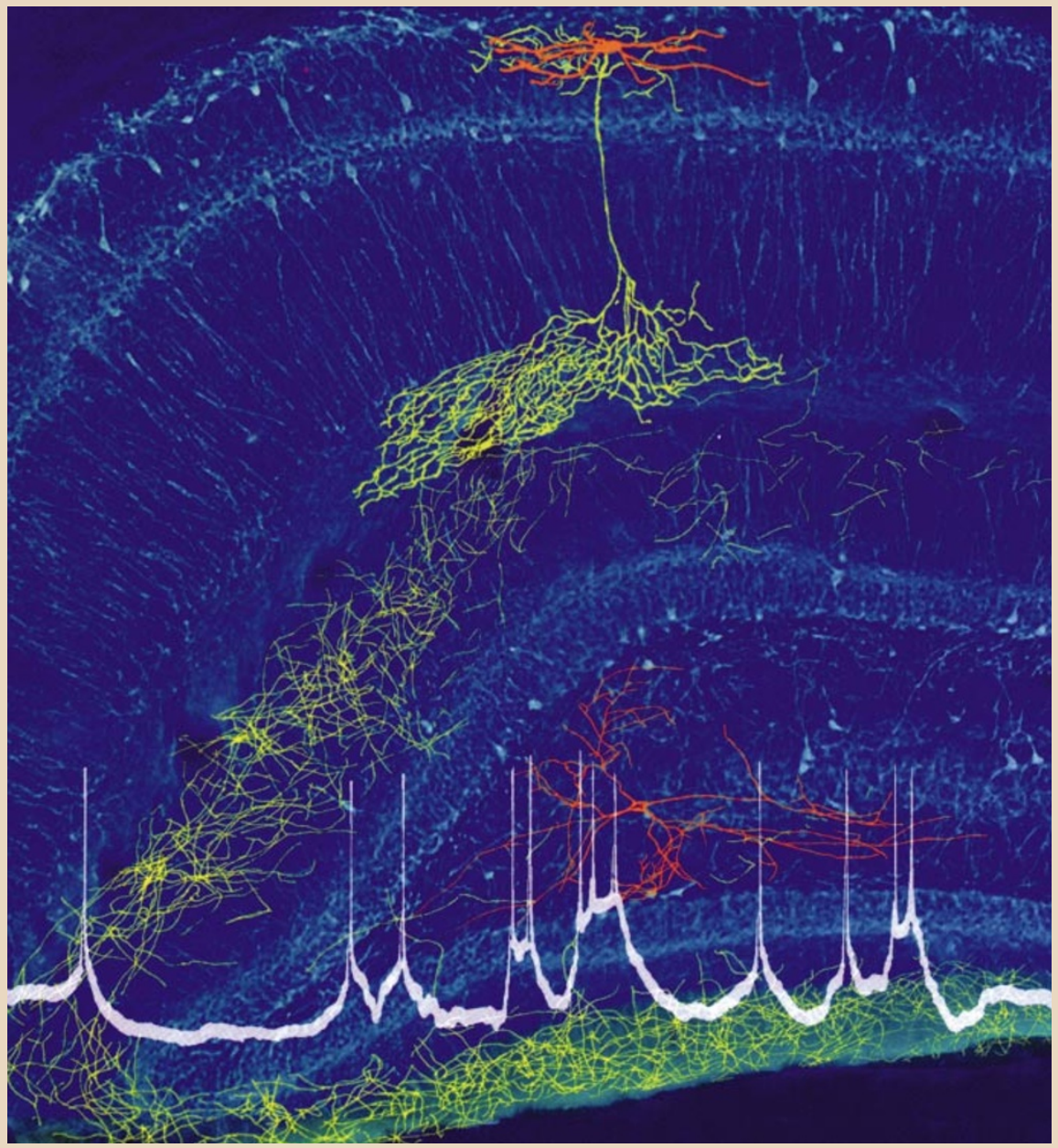

\title{
Looking closely at neuroscience
}

This section through the immunostained hippocampus of a rat adorns the cover of Foundations of Neurobiology (W. H. Freeman, $\$ 55.95, \mathfrak{E 3 2 . 9 5 )}$. This broad-based neurobiology textbook, written by Fred Delcomyn for students early in their training, will prepare them for further study in neuroscience. It is clearly laid out, with key terms in bold and generous use of tables and illustrations, and contains a useful glossary. 
object to this convention, because it represents one more step away from the actual material, but it can be justified because it provides uniformity and a high level of illustration that is almost always lacking, even in major anatomical works.

The last part of each chapter summarizes functional aspects and the phylogenetic significance of the brains examined. It is here that the authors' scholarship shines most brightly. They present a balanced and comprehensive survey of current knowledge of the particular group of vertebrates described, rather than simply presenting the results of their own research. In rare cases, however, the authors adopt such a neutral position on critical issues that an informed reader will be frustrated.

The third part of this work focuses on brain size in vertebrates, and attempts to recognize major patterns or principles of organization of the major brain divisions. The chapter on brain size beautifully summarizes a vast literature, and the authors rightfully conclude that no single biological factor is likely to account for the vast range of brain sizes among vertebrates. The final chapter, "The Meaning of it All", gives a bird's eye view of the vast range of brain variation that exists among living vertebrates. In so doing, it poses questions that should continue to excite future generations rather than capping the field with a second tombstone.

Glenn Northcutt is in the Department of

Neurosciences, University of California, San Diego, 9500 Gilman Drive, La Jolla, California $92093-$ 0201, USA.

\section{Is meta better?}

\section{How Science Takes Stock: The Story of Meta-Analysis}

by Morton Hunt

Russell Sage Foundation: 1997. Pp. 210. $\$ 29.95, £ 24$

\section{Steve Blinkhorn}

A new kind of alchemy is abroad in the world. Arcane, esoteric and mesmerizing, it promises not to turn base metal into gold, nor to provide an elixir of youth, but to transmute statistical sows' ears into scientific silk purses. Meta-analysis, the systematic synthesis of otherwise inconclusive research findings into hard results, has, in the space of barely two decades, come from a standing start to challenge the blind clinical trial as the principal arbiter of truth and the touchstone of knowledge across a range of biomedical and social sciences.

Precisely because it is in these fields that hard, fast and exact findings are hard to come by, methodology meets morality with peculiar poignancy. Why go to the trouble and expense of blind experimentation, and subject a substantial proportion of a research

\section{Living with the moose}

The North American moose, Alces alces, is the largest living deer, and roams freely across a band of forest covering Newfoundland, the Rocky Mountains, Alaska and as far south as Colorado. If the one on the right seems a little wary, it is perhaps no surprise. Prized by native Americans and an important part of their culture, the moose was hunted by European settlers almost to extinction by the start of this century; the population has since recovered to around a million. Hunting still goes on (but licensed now), and man kills a further 3,500 in road accidents each year. Albert W. Franzmann and Charles C. Schwartz have brought together 21 wildlife researchers to describe the moose's biology and ecology and analyse the strategies of managing and living alongside the animal. The result is the comprehensive Ecology and Management of the North American Moose (Wildlife Management Institute / Smithsonian Institution Press,

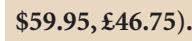

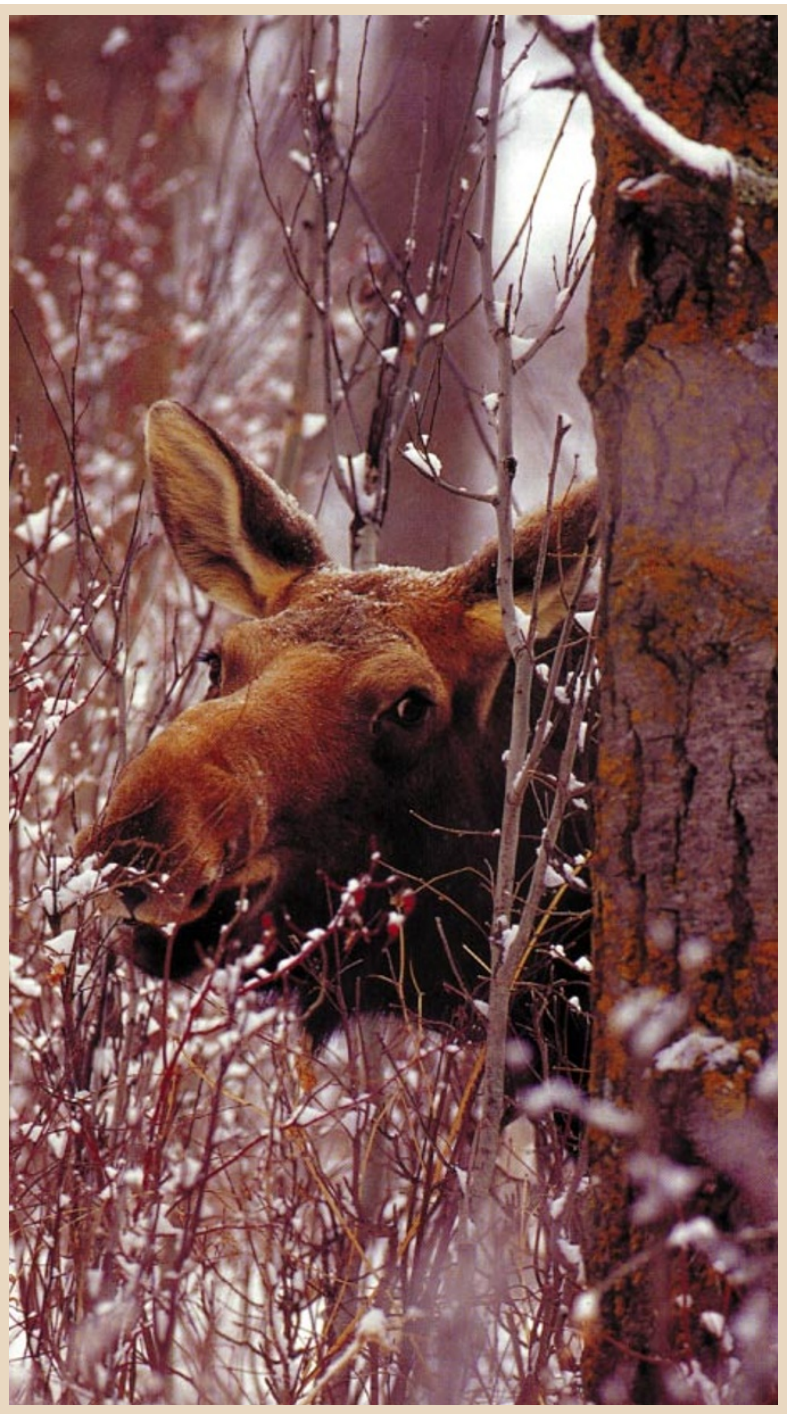

sample to suboptimal treatment, when a little fastidious dredging through inconclusive research literature can be turned, with a little statistical wizardry, into a clear result? The prospect of being able to complete a paper with the words "further research is not necessary" can be too tantalizing to ignore, particularly where conclusions affect the lives and prospects of real people.

The practice of meta-analysis is by no means a soft option. Done properly it requires long and tedious library research to identify studies that meet the criteria for statistical synthesis. In many respects the statistical procedures that form the visible element of meta-analysis are the least troublesome part of the process. The problem for researchers - and journal editors - is that the process of screening suitable results for inclusion in the synthesis is necessarily laborious and painstaking, not to say difficult to replicate. Journal referees can hardly be expected to undertake sufficient checking to ensure that the research literature has thestatus claimed by the meta-analyst. The audience is therefore more than usually reliant on the honesty, accuracy and competence of the research team in evaluating their claims.
An accessible and balanced account of the practice of meta-analysis may be thought overdue. Sadly, this book does not fit the bill. An openly partisan, not to say propagandist, introduction to the field, it has the same cringe-inducing quality found in certain excessively contemporary translations of the New Testament of the Bible.

Morton Hunt has provided subversive footnotes; subversive, that is, of his own purpose. For instance, in a dustjacket puff, Richard Light, one of the leading figures in meta-analysis, tells us that Hunt has "gotten all the important details right". But a footnote in the text tells us that in conventional hypothesis testing " $p$ is the probability that [the] null hypothesis is true". If an understanding of the rudiments of inferential statistics is as unimportant to meta-analysis as this potted travesty of wisdom would suggest, we might as well abandon the pretence that undergraduates can get to grips with conventional hypothesis testing.

A little later in the book, the tale is told of how meta-analysis was first developed to rebut Hans Eysenck's claim that psychotherapy is ineffective. A footnote explains that the British use of the term 'psychotherapy' 